\title{
Twenty-four-hour Requirement of Rescue Analgesia after Upper Limb Surgery under Supraclavicular Brachial Plexus Block: A Role of Nalbuphine as an Adjuvant to Levobupivacaine
}

Shivika Aggarwal ${ }^{1}$, Anita Kumari ${ }^{2}$, Ruchi Gupta ${ }^{3}$

\begin{abstract}
Background: Opioids have been used with peripheral nerve blocks for its synergistic effect to enhance the postoperative analgesic effectiveness of regional block. Nalbuphine, a newer opioid with an analgesic equivalence of morphine, has a ceiling effect on respiratory depression. The aim of the present study was to evaluate the effect of nalbuphine when used as an adjuvant to levobupivacaine on 24-hour postoperative analgesic requirement after brachial plexus block (BPB).

Materials and methods: Sixty adult patients of either sex of American Society of Anesthesiologists (ASA) physical status I and II were randomized into two groups of 30 each to receive a total volume of $30 \mathrm{~mL}$ of study drug for supraclavicular brachial plexus block (SBPB): Group N-29 mL of $0.5 \%$ levobupivacaine with $1 \mathrm{~mL}$ of $10 \mathrm{mg}$ nalbuphine; Group S- $29 \mathrm{~mL}$ of $0.5 \%$ levobupivacaine with $1 \mathrm{~mL}$ of normal saline. Patients observed for 24-hour postoperative mean requirement of rescue analgesia, that is, diclofenac sodium, block characteristics, visual analog scale (VAS) scores, and the associated complications.

Results: Demographic profile was comparable between the two groups. The mean dose of rescue analgesic required between the groups $\mathrm{N}$ and S was $127.5 \pm 34.96 \mathrm{mg}$ and $150 \pm 37.5 \mathrm{mg}(p=0.000)$, respectively. The average VAS score at different time intervals was highly significant between the two groups $(p<0.05)$. Similarly, block characteristics were statistically significant between the two groups; that is, onset was early, but the duration was prolonged in group $\mathrm{N}(p<0.05)$. Complications, although more in group $\mathrm{N}$, were minor and statistically insignificant $(p>0.05)$. Conclusion: Nalbuphine $10 \mathrm{mg}$ as an adjunct to $0.5 \%$ levobupivacaine significantly reduced the requirement of rescue analgesia compared to placebo, with no significant major adverse effects.
\end{abstract}

Keywords: Analgesia, Levobupivacaine, Nalbuphine hydrochloride, Postoperative pain, Supraclavicular brachial plexus.

AMEI's Current Trends in Diagnosis \& Treatment (2021): 10.5005/jp-journals-10055-0115

\section{INTRODUCTION}

Opioids have been studied, used, and misused for their role as adjuvants to bupivacaine for peripheral nerve blocks, which results in significant morbidity and mortality if overused. Indiscriminate prescription in the perioperative period may ultimately lead to addiction, overdose, and death from the prescribed opioids. In search of narcotic analgesics with less abuse potential, a number of synthetic opiates were developed. One such opioid, nalbuphine, has a strong analgesic property with mixed k agonist and $\mu$ antagonist and exhibits a ceiling effect on respiratory depression. ${ }^{1,2}$ It is effective as an adjuvant to local anesthetics as it significantly prolongs the duration of the block in various neuraxial techniques. ${ }^{3}$ A brachial plexus block (BPB) is used as anaesthesia and analgesia during surgery involving the upper limb and in acute pain conditions, and it is mostly used by anesthesiologists. Levobupivacaine is considered a safer local anesthetic agent for neuraxial anaesthesia techniques, but data are limited in peripheral blocks as compared to bupivacaine. Also, opioid-free anaesthesia is emerging as a new stimulating research perspective that aims at using nonopioids in the postoperative period as rescue analgesia. Hence, the present study was carried out to evaluate the analgesic effect of nalbuphine as an adjuvant to levobupivacaine for reducing the mean postoperative requirement of rescue analgesia in upper limb surgeries under supraclavicular brachial plexus block (SBPB) as
${ }^{1-3}$ Department of Anaesthesia, Sri Guru Ram Das Institute of Medical Sciences and Research, Amritsar, Punjab, India

Corresponding Author: Ruchi Gupta, Department of Anaesthesia, Sri Guru Ram Das Institute of Medical Sciences and Research, Amritsar, Punjab, India, Phone: +91 9814320805, e-mail: drruchisgrd@gmail.com How to cite this article: Aggarwal S, Kumari A, Gupta R. Twenty-fourhour Requirement of Rescue Analgesia after Upper Limb Surgery under Supraclavicular Brachial Plexus Block: A Role of Nalbuphine as an Adjuvant to Levobupivacaine. AMEl's Curr Trends Diagn Treat 2021;5(1):16-20.

Source of support: Nil

Conflict of interest: None

a primary outcome. The postoperative absolute visual analog scale $(V A S)^{4}$ scores were evaluated as a secondary outcome.

\section{Materials and Methods}

A double-blind, randomized, prospective placebo-controlled interventional study was carried out at a tertiary care hospital in North India with 60 patients of American Society of Anesthesiologist $(A S A)^{5}$ grade I and II of either sex, aged 18 to 60 years, undergoing various surgeries on the upper limb under SBPB. After ethical 
committee approval (SGRD/IEC patho/166/19) and written informed consent from the patients, enrollment was done. The patients with local infection at the injection site, coagulopathy, patients on anticoagulants, allergy to any local anesthetic and study drug, and those who refused the procedure were excluded from the study.

These patients, by using computer-generated random number table, were allocated to one of the groups of 30 each: Group N $(n=30)$ who received $29 \mathrm{~mL}$ of $0.5 \%$ levobupivacaine with $1 \mathrm{~mL}$ of $10 \mathrm{mg}$ nalbuphine and group $\mathrm{S}(n=30)$ who received $29 \mathrm{~mL}$ of $0.5 \%$ levobupivacaine with $1 \mathrm{~mL}$ of normal saline, to make a total volume of $30 \mathrm{~mL}$ in both the groups. After the random number allocation of groups, a nonparticipant technician was asked to prepare the study drug and hand over to anesthesiologist performing the block. The patients as well as the assessor was blinded to the drug solution.

On achieving adequate fasting for $6-8$ hours on the day of surgery, patients received midazolam injection 1-2 mg intravenously 15 minutes prior to surgery. They were explained in their vernacular language about the anesthetic technique and VAS score ${ }^{4}$ on the scale of $0-100$ with 0 as no pain and 100 as maximum pain one can experience. The VAS is $100 \mathrm{~mm}$ line with anchor statements on the left (no pain) and on the right (extreme pain). The patient is asked to mark their current pain level on the line. Baseline monitoring included heart rate, blood pressure, and oxygen saturation.

All the patients received BPB through the supraclavicular approach by an experienced anesthesiologist using the nerve stimulator technique. The patients were placed in a supine position with the head turned away from the side of the block, and lignocaine injection $1 \mathrm{~mL}$ was injected at the site of stimulating needle puncture. Neural localization was achieved by using a nerve locator (Stimuplex, B. Braun, Germany) with 22-gauge, short-beveled, nerve-stimulating needle (Stimuplex Ultra, B. Braun, Germany) inserted in caudal, slightly medial, and posterior direction. The needle was then connected to the negative lead of the nerve locator, and with a current setting of 2-3 mA, the contractions distal to the elbow were observed. Then, the current was reduced to $0.5 \mathrm{~mA}$, and the study drug solution was injected slowly following negative aspiration.

The onset of sensory and motor block was evaluated every 5 minutes for 20 minutes by Hollmen scale ${ }^{6}$ for sensory effect and modified Bromage scale ${ }^{7}$ for motor effect, until the block was finally established. The duration of sensory block was taken as time elapsed between injection of drug and return of pinprick sensation. Similarly, the duration of motor block was considered as the time interval between injection of drug and complete return of motor power. Postoperative pain was evaluated using VAS score (0-100), which was recorded at 0, 2, 4, 6, 8, 12, and 24 hours after the surgery. When VAS reached 40 , the rescue analgesia in the form of intravenous $75 \mathrm{mg}$ diclofenac was administered. Hemodynamics were recorded both intraoperatively and postoperatively. The complications such as pneumothorax, hematoma, postoperative paresthesia, respiratory depression, excessive sedation, nausea, and vomiting were observed.

Sample size calculation was done using a mean dose of rescue analgesia as a primary outcome from a previous study done by Das et al. With $80 \%$ power of the study and 0.05 probability of alpha error, the sample size was calculated to be 26 . Taking a dropout rate of $10-15 \%$, the recruitment target was kept 30 patients per group.

Data were entered into Microsoft Excel spreadsheet and analyzed using SPSS Statistics-26 version to draw relevant conclusions. The observations were tabulated in the form of mean \pm standard deviation (SD). For parametric data, Student's paired " $t$ " test was applied. Categorical variables were correlated using chi-square test. The level of significance was determined as " $p$ " value with $p<0.05$ as significant and $p<0.001$ as highly significant.

\section{Results}

In the present study, 66 patients who met the inclusion as well as exclusion criteria were assessed, of which 60 patients were randomized for the study (Flowchart 1). Demographic data including age, sex, weight, ASA classification, and duration of surgery were comparable statistically (Table 1).

Group N required a lesser number of doses of rescue analgesia as well as the total mean requirement of diclofenac than the patients in group $S$ in the first 24 hours of postoperative period $(p<0.05)$ (Table 2). In the postoperative period, the difference in mean VAS score at different time intervals was highly significant between the two groups ( $p<0.001$ ) (Fig. 1).

The intraoperative block characteristics showed a rapid onset of both motor and sensory block in group $\mathrm{N}$ as compared to group $\mathrm{S}(p<0.05)$. Even the duration of motor and sensory block in group $\mathrm{N}$ was highly significant compared to group $\mathrm{S}$ $(p<0.001)$ (Table 3$)$. All patients remained hemodynamically

Flowchart 1: Consort flow diagram

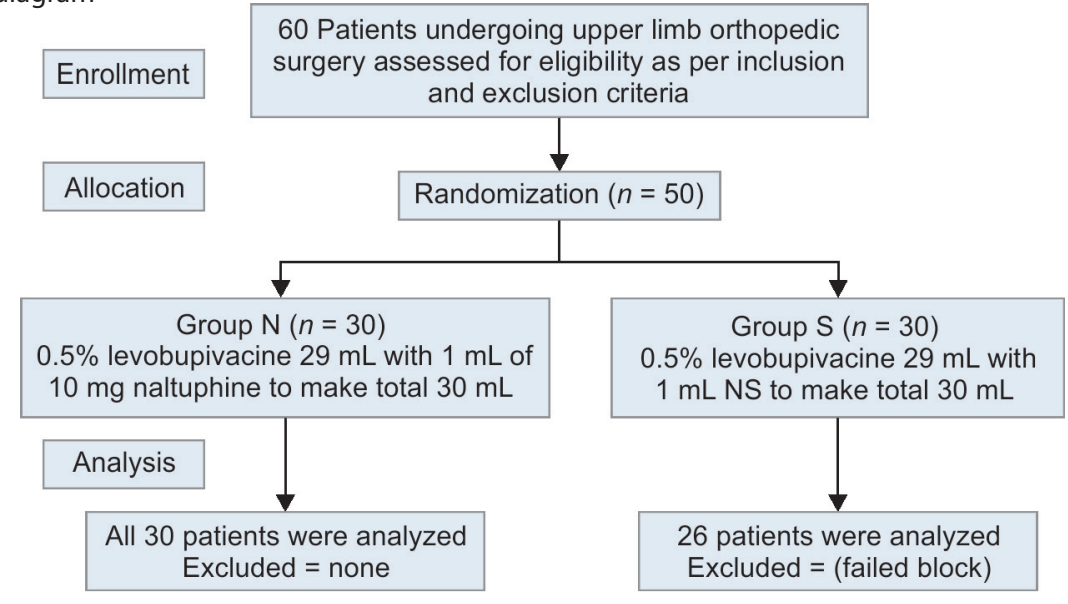


Requirement of Rescue Analgesia after Supraclavicular Brachial Plexus Block

Table 1: Demographic data of patients in each group

\begin{tabular}{lccl}
\hline & Group N $(n=30)$ & Group S $(n=30)$ & $p$-value \\
\hline Age (years) & $36.47 \pm 13.4$ & $38.1 \pm 14.61$ & 0.653 \\
Weight $(\mathrm{kg})$ & $63.33 \pm 8.04$ & $63.23 \pm 6.94$ & 0.959 \\
Height $(\mathrm{cm})$ & $161.53 \pm 4.55$ & $162.87 \pm 5.06$ & 0.287 \\
$\begin{array}{l}\text { Duration of surgery } \\
\text { (minutes) }\end{array}$ & $101 \pm 17.64$ & $105.17 \pm 14.11$ & 0.316 \\
BMI $\left(\mathrm{kg} / \mathrm{m}^{2}\right)$ & $24.31 \pm 3.27$ & $23.91 \pm 3.11$ & 0.631 \\
ASA $(\mathrm{I} / \mathrm{II})$ & $19 / 11$ & $20 / 10$ & 0.598 \\
Gender $(\mathrm{M} / \mathrm{F})$ & $22 / 8$ & $16 / 14$ & 0.791 \\
\hline
\end{tabular}

Table 2: Mean rescue analgesia requirement in both the groups

\begin{tabular}{llll}
\hline & & & $p$-value \\
& Group N $(n=30)$ & Group S $(n=26)$ & Nvs S \\
\hline $\begin{array}{l}\text { Mean dose of } \\
\text { diclofenac }(\mathrm{mg})\end{array}$ & $127.5 \pm 34.96$ & $150 \pm 37.5$ & $0.040^{*}$ \\
\hline
\end{tabular}

Table 3: Perioperative block characteristics in each group

\begin{tabular}{lcll}
\hline Groups & $\begin{array}{l}\text { Group N } \\
(n=30)\end{array}$ & $\begin{array}{l}\text { Group S } \\
(n=26)\end{array}$ & $\begin{array}{l}\text { Group N vs } \\
\text { Group S } \\
(p \text {-value) }\end{array}$ \\
\hline $\begin{array}{l}\text { Onset of sensory } \\
\text { block mean } \pm \text { SD } \\
\text { (minutes) }\end{array}$ & $13.53 \pm 4.27$ & $16.67 \pm 5.35$ & $0.025^{*}$ \\
$\begin{array}{l}\text { Onset of motor } \\
\text { block mean } \pm \text { SD } \\
\text { (minutes) }\end{array}$ & $16.7 \pm 4.8$ & $21.7 \pm 7.25$ & $0.002^{*}$ \\
$\begin{array}{l}\text { Duration of sensory } \\
\text { block (minutes) }\end{array}$ & $519.67 \pm 76.18$ & $445.2 \pm 132.1$ & $0.015^{*}$ \\
$\begin{array}{l}\text { Duration of motor } \\
\text { block (minutes) }\end{array}$ & $469.33 \pm 79.44$ & $421.2 \pm 125.34$ & $0.048^{*}$ \\
$\begin{array}{l}\text { Duration of } \\
\text { analgesia (minutes) }\end{array}$ & $618 \pm 62.33$ & $508 \pm 133.51$ & $0.000^{* *}$ \\
\hline Signifint: "Highty sing & & & \\
\hline
\end{tabular}

"Significant; ${ }^{* *}$ Highly significant

\section{"Significant}

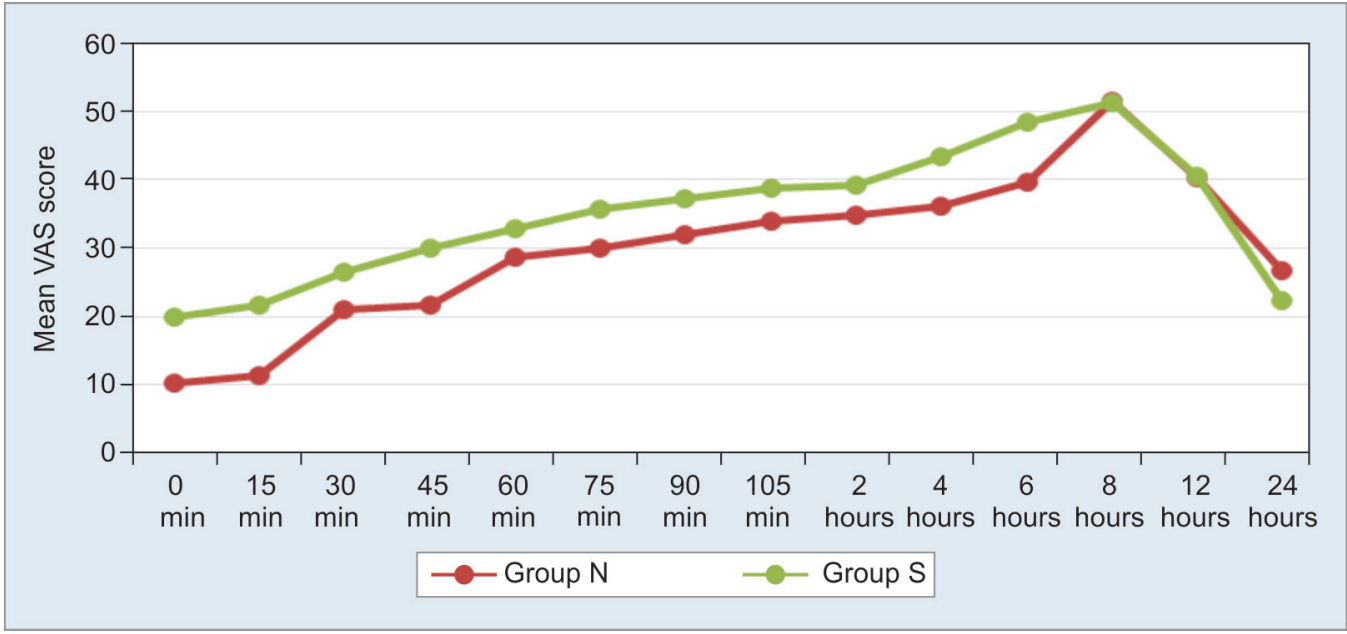

Fig. 1: Mean VAS score in each group at different time intervals

stable in both the groups during the intraoperative and postoperative period as assessed by mean heart rate and mean arterial pressure (MAP) (Fig. 2).

The complications such as nausea, vomiting, sedation, and pruritis were more in group $\mathrm{N}$, but statistically insignificant as compared to group $S(p>0.05)$ (Table 4).

\section{Discussion}

SBPB in upper limb surgery in a meta-analysis was found to provide effective block along with reduced 24-hour postoperative pain scores and consumption of opioids. ${ }^{8}$ Adjuvants, such as opioids, ${ }^{9}$ alpha 2 blockers, ${ }^{10}$ magnesium sulfate, ${ }^{11}$ etc., have been used to improve block characteristics as well as increase the duration of postoperative analgesia. The opioids like tramadol, ${ }^{12}$ fentanyl, ${ }^{13}$ morphine, ${ }^{14}$ etc., when used as adjuvants to bupivacaine solutions, prolonged the duration of pain relief, thus, reducing the requirement of intravenous postoperative analgesics. But these have disadvantages like increased incidence of nausea, vomiting, respiratory depression, and itching. So, nalbuphine, a 14-hydroxymorphine derivative with a strong analgesic property having mixed $\kappa$ agonist and $\mu$ antagonist activity, has been studied by various authors. It has an equal analgesic effect as morphine, but possesses a ceiling effect on respiration, thus increasing safety. ${ }^{15}$ Gupta et al. studied nalbuphine as an adjuvant to $0.5 \%$ bupivacaine and concluded that combination significantly extended the duration of analgesia of BPB with no rescue analgesia requirement. ${ }^{16}$ Recently, levobupivacaine proved a better alternative to bupivacaine in SBPB due to its cardiac stable property. ${ }^{17}$ Nalbuphine has been used in various doses to improve its efficacy. ${ }^{18}$

So, in our study, $10 \mathrm{mg}$ nalbuphine was added to $0.5 \%$ levobupivacaine that led to a reduced number of doses of rescue analgesia postoperatively and an overall lesser requirement of the total mean dose of diclofenac. The dose of nalbuphine was selected from previous studies that used $10 \mathrm{mg}$ dose. ${ }^{19}$ We had also selected this dose, which is a slightly lesser dose of a drug to be on a safer side.

Overall, the duration of analgesia was also prolonged in the nalbuphine group as compared to the placebo group. There were lesser VAS scores in group $\mathrm{N}$ indicating better quality of analgesia. Das et al. showed that the nalbuphine group required less amount of diclofenac sodium injection as rescue analgesics with lesser pain scores than patients in the control group in the first 24 hours of the postoperative period..$^{20}$ Chiruvella 


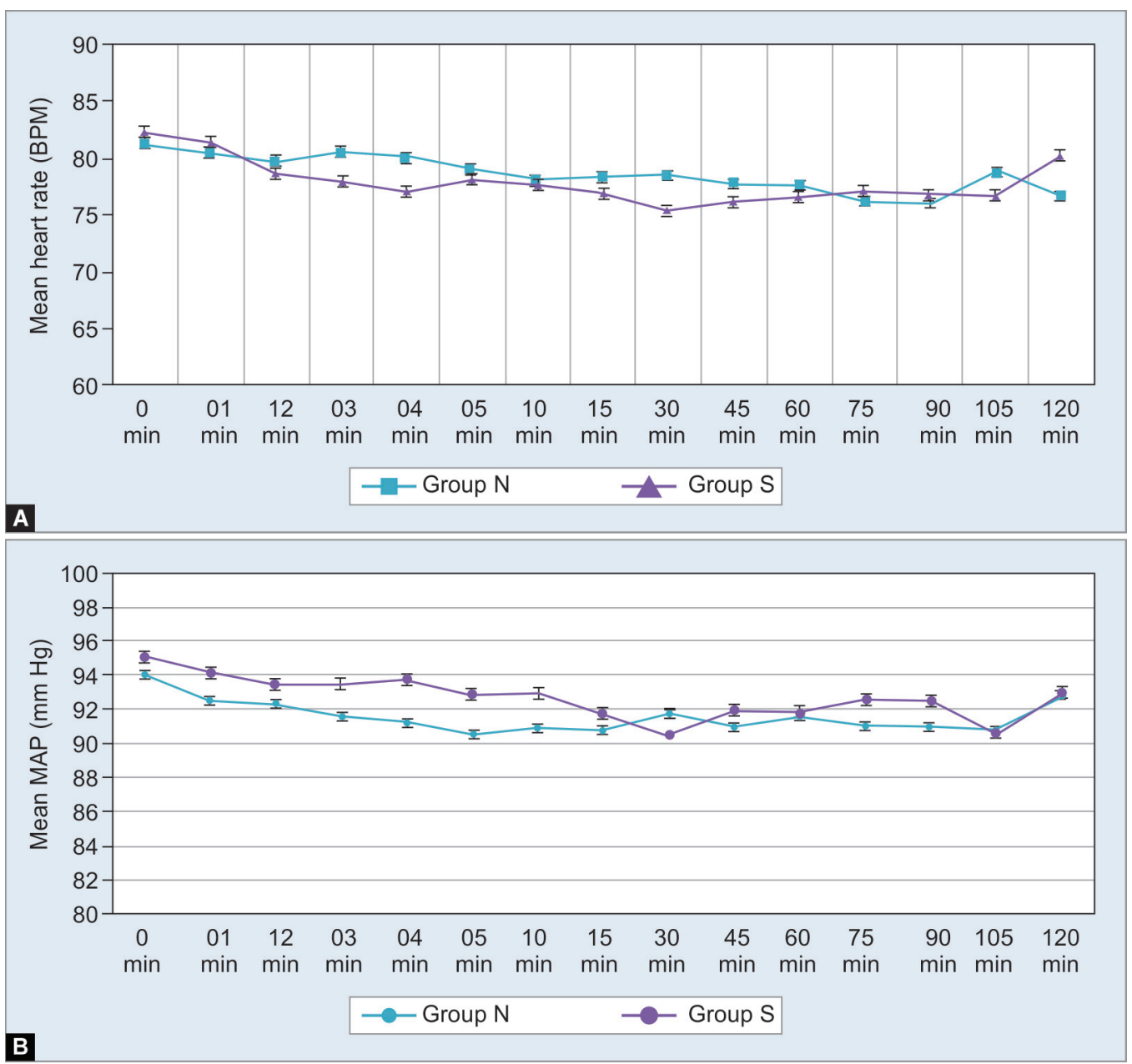

Figs 2A and B: (A) Mean intraoperative HR (bpm) in each group at various time intervals; (B) Mean intraoperative MAP (mm Hg) in each group at various time intervals

Table 4: Comparison of side effects in each group

\begin{tabular}{|c|c|c|c|c|c|}
\hline \multirow[b]{2}{*}{ Adverse effects } & \multicolumn{2}{|c|}{ Group N $(n=30)$} & \multicolumn{2}{|c|}{ Group S $(n=26)$} & \multirow[b]{2}{*}{$p$-value } \\
\hline & $n$ & $\%$ & $n$ & $\%$ & \\
\hline Hematoma formation & 1 & 3.3 & - & - & 0.867 \\
\hline Paresthesia & 1 & 3.3 & - & - & 0.573 \\
\hline Pneumothorax & - & - & - & - & - \\
\hline Bradycardia & 2 & 6.7 & - & - & 0.736 \\
\hline Hypotension & 1 & 3.3 & - & - & 0.312 \\
\hline Nausea and vomiting & 5 & 16.7 & 3 & 12.0 & 0.781 \\
\hline Sedation & 4 & 13.3 & 1 & 4.0 & 0.271 \\
\hline Respiratory depression & - & - & - & - & - \\
\hline Pruritus & 5 & 16.7 & - & - & 0.096 \\
\hline Dry mouth & 4 & 13.3 & 2 & 8.0 & 0.406 \\
\hline
\end{tabular}

et al. demonstrated that $10 \mathrm{mg}$ dose of nalbuphine had better analgesic efficacy with lesser or no requirement of rescue analgesia than $5 \mathrm{mg}$ dose. ${ }^{21}$

Not only this combination provided better postoperative analgesia but also led to improved intraoperative block characteristics. $^{20,22,23}$ The onset of sensory and motor block was earlier, and the duration of sensory block was prolonged. However, the motor effect was also delayed, which could prolong the discomfort as well as delay arm physiotherapy in some patients. As opioids could exert local anesthetic action via the closure of sodium channels embedded in the nerve membrane, they are able to prolong motor and sensory blocks. ${ }^{24}$ The addition of nalbuphine to levobupivacaine did not affect the hemodynamics at any time interval during the entire study period, as also observed by many authors..$^{20,21,25}$

Drug-related complications like nausea, vomiting, pruritis, and dry mouth were more in the nalbuphine group but did not cause any significant discomfort to the patients. These could be managed conservatively. Similar complications were observed by other authors. ${ }^{16,20,26}$ Other side effects like dizziness, headache, sweating, and facial flushing were not observed.

SBPB using nerve localization technique with a peripheral nerve stimulator (PNS) for upper limb surgeries have been used extensively for two decades before the advent of ultrasound (US). The use of US could have improved the outcome of the present study further, but its unavailability during the designing phase became one of our limitations. Moreover, a meta-analysis by Casati et al. found equivalence between PNS and US-guided blocks in expert hands, especially where multiple injections were required for blocking brachial plexus nerves. ${ }^{27}$ 


\section{CONCLUSION}

The addition of $10 \mathrm{mg}$ nalbuphine hydrochloride to levobupivacaine $0.5 \%$ solution in SBPB reduced the mean 24 -hour requirement of rescue analgesia during the postoperative period, improved VAS scores, and prolonged the duration of analgesia with minimal insignificant adverse effects.

\section{References}

1. Pick CG, Paul D, Pasternak GW. Nalbuphine, a mixed kappa 1 and kappa 3 analgesic in mice. J Pharmacol Exp Ther 1992;262(3): 1044-1050. PMID: 1326621.

2. Klepper ID, Rosen M, Vickers MD, et al. Respiratory function following nalbuphine and morphine in anaesthetized man. Br J Anaesth 1986;58(6):625-629. DOI: 10.1093/bja/58.6.625.

3. Ahmed F, Narula H, Khandelwal M, et al. A comparative study of three different doses ofnalbuphine as an adjuvant to intrathecal bupivacaine for postoperative analgesia in abdominal hysterectomy. Indian J Pain 2016;30(1):23-28. DOI: 10.4103/0970-5333.173457.

4. Jensen MP, Karoly P, Braver S. The measurement of clinical pain intensity: a comparison of six methods. Pain 1986;27(1):117-126. DOI: 10.1016/0304-3959(86)90228-9.

5. De Cassai A, Boscolo A, Tonetti T, et al. Assignment of ASA-physical status relates to anesthesiologists' experience: a survey-based national-study. Korean J Anesthesiol 2019;72(1):53-59. DOI: 10.4097/ kja.d.18.00224.

6. Lee R, Kim YM, Choi EM, et al. Effect of warmed ropivacaine solution on onset and duration of axillary block. Korean J Anesthesiol 2012;62(1):52-56. DOI: 10.4097/kjae.2012.62.1.52.

7. Malinzak EB, Gan TJ. Regional anesthesia for vascular access surgery. Anaeth Analg 2009;109(3):976-980. DOI: 10.1213/ane. 0b013e3181adc208.

8. Schubert AK, Dinges $\mathrm{HC}$, Wulf $\mathrm{H}$, et al. Interscalene versus supraclavicular plexus block for the prevention of postoperative pain after shoulder surgery: a systematic review and metaanalysis. Eur J Anaesthesiol 2019;36(6):427-435. DOI: 10.1097/ EJA.0000000000000988.

9. Kumari A, Chhabra H, Gupta R, et al. Comparative study of effectiveness of tramadol and butorphanol as adjuvants to levobupivacaine for supraclavicular brachial plexus block. Anesth Essays Res 2019;13(3):446-451. DOI: 10.4103/aer.AER_110_19.

10. Patil KN, Singh ND. Clonidine as an adjuvant to ropivacaine-induced supraclavicular brachial plexus block for upper limb surgeries. J Anaesthesiol Clin Pharmacol 2015;31(3):365-369. DOI: 10.4103/09709185.161674.

11. Dogru K, Yildirim D, Ulgey A, et al. Adding magnesium to levobupivacaine for axillary brachial plexus block in arteriovenous fistule surgery. Bratisl Lek Listy 2012;113(10):607-609. DOI: 10.4149/ bll_2012_136.

12. Nagpal V, Rana S, Singh J, et al. Comparative study of systemically and perineurally administered tramadol as an adjunct for supraclavicular brachial plexus block. J Anaesthesiol Clin Pharmacol 2015;31(2): 191-195. DOI: 10.4103/0970-9185.155147.

13. Rajkhowa T, Das N, Parua S, et al. Fentanyl as an adjuvant for brachial plexus block: a randomized comparative study. Int J Clin Trials 2016;3(2):64-67. DOI: 10.18203/2349-3259.ijct20160996.
14. Mohamed KH, Abdelrahman KA, Elameer AN, et al. Morphine as an adjuvant to local anesthetics in axillary brachial plexus block in forearm and hand surgery. J Curr Med Res Pract 2019;4(2):131-136. DOI: 10.4103/JCMRP.JCMRP_35_19.

15. Gunion MW, Marchionne AM, Anderson TM. Use of the mixed agonist-antagonist nalbuphine in opioid based analgesia. Acute Pain 2004;6(1):29-39. DOI: 10.1016/j.acpain.2004.02.002.

16. Gupta K, Jain M, Gupta PK, et al. Nalbuphine as an adjuvant to $0.5 \%$ bupivacaine for ultrasound-guided supraclavicular brachial plexus blockade. Indian J Pain 2016;30(3):176-180. DOI: 10.4103/0970-5333.198024.

17. Kothari R, Fernandes $S$, Atkar A, Paliwal S. A prospective observational study to compare the effectiveness of bupivacaineversuslevobupivacaine in supraclavicular brachial plexus block. Int J Contemp Med Res. 2020;7(9):11-6. DOl: org/10.21276/ijcmr.2020.7.9.26.

18. Tejaswi S, Sree MS. A comparative study of varying doses of nalbuphine $5 \mathrm{mg}$ vs $10 \mathrm{mg}$ with ropivacaine in supraclavicular brachialplexus block: a prospective, double-blind, randomized trial. IOSRJ J Med Dent Sci. 2019;18(11):45-49. DOI: 10.9790/08531811074549.

19. Kalika P, Xue R, Zheng J, et al. Efficacy of nalbuphine as an adjuvant to ropivacaine in ultrasound-guided supraclavicular brachial block: a prospective randomized controlled study. Clin J Pain 2020;36(4):267-272. DOI: 10.1097/AJP.0000000000000803.

20. Das A, RoyBasunia $S$, Mukherjee $A$, et al. Perineural nalbuphine in ambulatory upper limb surgery: a comparison of effects of levobupivacaine with and without nalbuphine as adjuvant in supraclavicular brachial plexus block - a prospective, double-blinded, randomized controlled study. Anesth Essays Res 2017;11(1):40-46. DOI: 10.4103/0259-1162.200225.

21. Chiruvella S, Konkyana SK, Nallam SR, et al. Supraclavicular brachial plexus block: comparison of varying doses of nalbuphine combined with levobupivacaine: a prospective, double-blind, randomized trial. Anesth Essays Res 2018;12(1):135-139. DOI: 10.4103/aer.AER_197_17.

22. Rehab OM, Al Shreif SI, Amr YM, et al. Different low doses of levobupivacaine $0.5 \%$ with nalbuphine in spinal anesthesia for transurethral resection of prostate surgery. Tanta Med J 2017;45(2):57-63. DOI: 10.4103/tmj.tmj_9_17.

23. Abdelhaq MM, Elramely MA. Effect of nalbuphine as adjuvant to bupivacaine for ultrasound-guided supraclavicular brachial plexus block. Open J Anesthesiol 2016;6(3):20-26. DOI:10.4236/ ojanes.2016.63004.

24. Likar R, Koppert W, Blatnig H, et al. Efficacy of peripheral morphine analgesia in inflamed, noninflamed and perineural tissue of dental surgery patients. J Pain Symptom Manage 2001;21(4):330-337. DOI: 10.1016/s0885-3924(01)00251-2.

25. Jain K, Sethi SK, Gupta S, et al. Efficacy of nalbuphine as an adjuvant to $0.5 \%$ ropivacaine for ultrasound-guided supraclavicular brachial plexus block in upper limb surgeries: a prospective randomized double-blind study. Indian Anaesth Forum 2019;20(2):82-88. DOI: 10.4103/ThelAForum.ThelAForum_31_19.

26. Nazir N, Jain S. Randomized controlled trial for evaluating the analgesic effect of nalbuphine as an adjuvant to bupivacaine in supraclavicular block under ultrasound guidance. Anesth Essays Res 2017;11(2):326-329. DOI: 10.4103/0259-1162.194590.

27. Fanelli G, Casati A, Garancini P, et al. Nerve stimulator and multiple injection technique for upper and lower limb blockade. Anesth Analg 1999;88(4):847-852. DOI: 10.1097/00000539-199904000-00031. 